\title{
In-situ TEM study of the Corrosion Behavior of Zry-4
}

\author{
Wayne Harlow ${ }^{1}$, Hessam Ghassemi ${ }^{1}$, and Mitra L. Taheri ${ }^{1}$ \\ ${ }^{1}$ Drexel University Department of Materials Science and Engineering
}

This research investigates the effect of texture and grain boundary character on the corrosion response of Zircaloy-4 (Zry-4) using an in situ environmental cell in a transmission electron microscope (TEM). The corrosion response was studied in an oxygen rich environment at elevated temperatures, and monitored in real time using TEM bright field imaging and diffraction to observe the transition of Zry- 4 from base metal to oxide.

Zircaloy-4 is a commonly used material for nuclear fuel rod cladding, due to its low neutron cross section and good corrosion properties[1]. However, corrosion is still a limiting factor in fuel rod lifespan, which limits the burn up which can be achieved. As attempts are made to increase fuel burn up to reduce waste, more aggressive environments are being used, which results in more severe corrosion problems. In addition, Zirconium alloys are under consideration for some proposed Generation IV reactors, which also place high demands on these materials due to extreme conditions[2,3]. The corrosion response of Zry-4 has been well characterized via ex-situ experiments that simulate the environment found in light water reactors[3-5]. Much work has been done on autoclave-corroded samples, and the final oxide structure is well understood. However, almost all experimentation has been done after long periods of corrosion, and the initial steps of corrosion are not well understood. In order to design these alloys to be more corrosion resistant, the first steps of corrosion need to be observed, so that the effects of grain boundaries and other microstructural features can be determined.

Using a Protochips ${ }^{\mathrm{TM}}$ in-situ environmental cell holder, in which gas and vapor can be introduced to the sample region in addition to temperature control; we have corroded FIB samples of Zry-4 in-situ to study the initial corrosion response of this alloy. Focused Ion Beam (FIB) samples will be prepared from boundaries of different orientations as identified by Electron Backscatter Diffraction (EBSD). These samples were then lifted on to SiN electron transparent windows for use in the gas cell holder, as seen in figure 1. Using Nanomegas, the initial boundary orientation will be determined along with the material composition. Following this initial characterization, the corrosion experiment will be conducted at elevated temperature in an oxygen rich gas environment. Following the corrosion experiment, Nanomegas will again be used to determine any change in orientation and to help determine final material composition. Figure 2 shows a TEM image of the structure seen in a FIB sample after a corrosion experiment. Following this, samples are removed from the SiN windows to allow for high-resolution imaging to better examine the structures formed during short-term corrosion.

In summary, through the use of in-situ TEM, the beginning steps of corrosion of Zry-4 were observed. In our initial results we have seen the formation of oxide grains approximately $20 \mathrm{~nm}$ in size as a result of the complete oxidation of the Zry-4 sample. This work is the start of an ongoing investigation into the initial corrosion behavior of Zry-4 and the effect of grain boundaries and texture on the corrosion behavior of this alloy. This research is funded by the Department of Energy's Nuclear Energy University Program (NEUP). The authors would like to thank Arthur Motta of Penn State University for providing the Zircaloy samples. 
[1] C.L. Whitmarsh, Review of Zircaloy-2 and Zircaloy-4 Properties Relevant to N.S. Savannah Reactor Design, 1962.

[2] DOE-NERAC, A Technology Roadmap for Generation IV Nuclear Energy Systems, 2002.

[3] A.T. Motta, A. Yilmazbayhan, M.J.G. da Silva, R.J. Comstock, G.S. Was, J.T. Busby, E. Gartner, Q. Peng, Y.H. Jeong, J.Y. Park, J. Nucl. Mater. 371 (2007) 61.

[4] A. Yilmazbayhan, E. Breval, A.T. Motta, R.J. Comstock, J. Nucl. Mater. 349 (2006) 265.

[5] D. Fruchart, P. Convert, G. Lelievre, 347 (2002) 288.

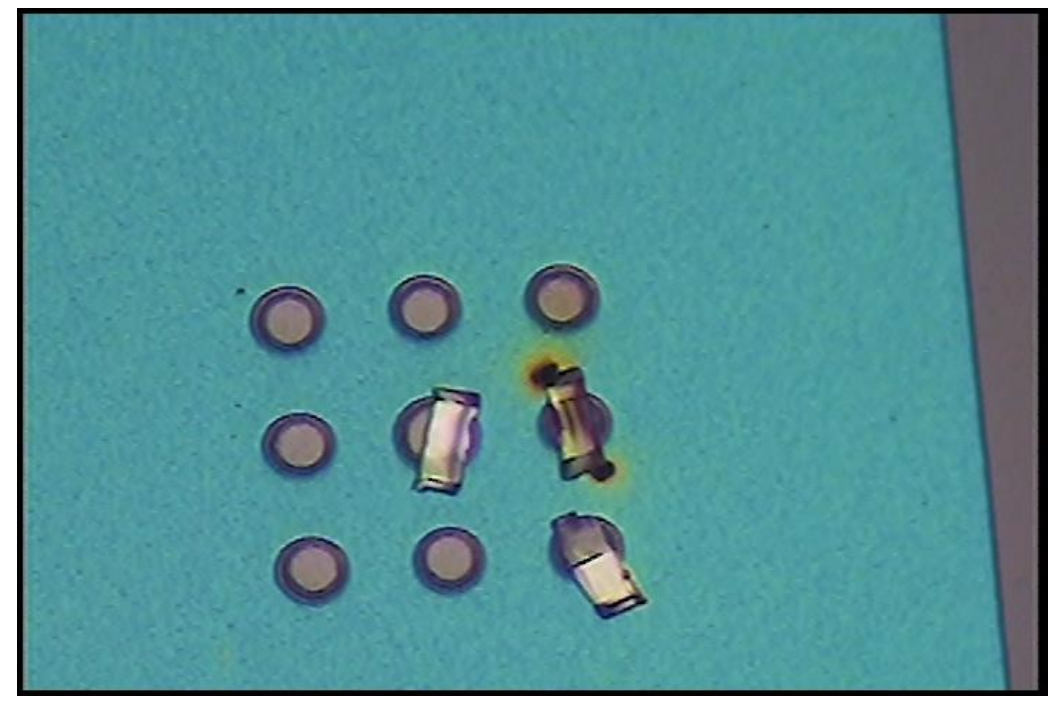

Figure 1: FIB samples placed on E-chip heating membrane over SiN electron transparent windows.

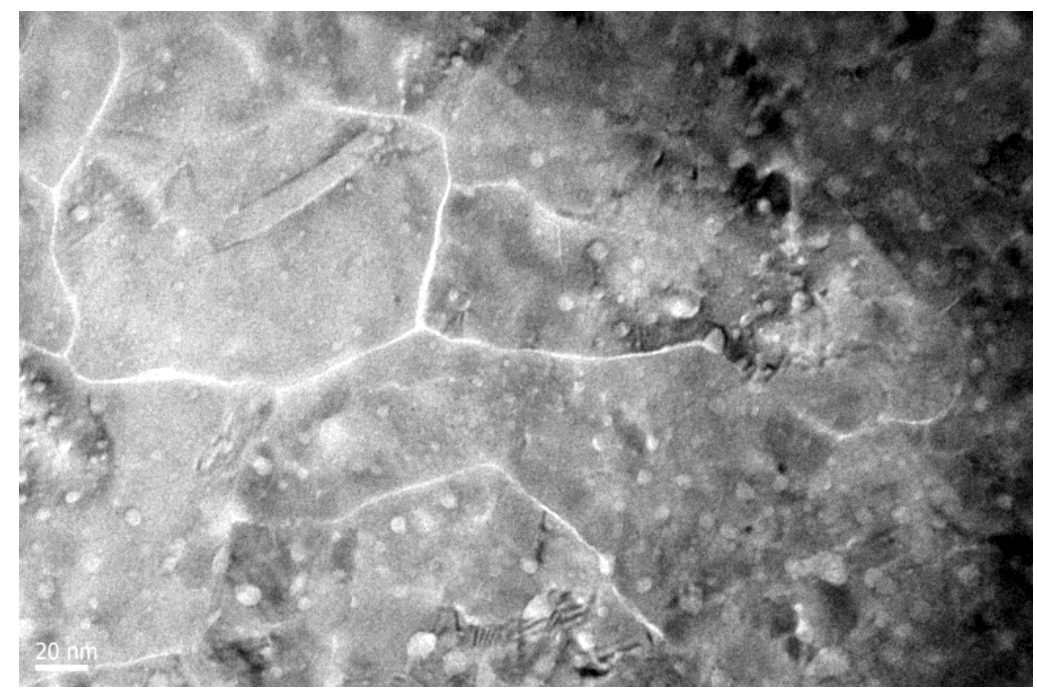

Figure 2: Image of sample following a corrosion experiment at elevated temperature in a oxygen rich gas environment. 